2 Mcneill RS. Effect of a $\beta$-adrenergic-blocking agent, propranolol, on asthmatics. Lancet 1964; 2: 1101-1102.

3 Callaerts-Vegh Z, Evans KL, Dudekula N, et al. Effects of acute and chronic administration of $\beta$-adrenoceptor ligands on airway function in a murine model of asthma. Proc Natl Acad Sci USA 2004; 101: 4948-4953.

4 Lin R, Peng H, Nguyen LP, et al. Changes in $\beta_{2}$-adrenoceptor and other signaling proteins produced by chronic administration of "B-blockers" in a murine asthma model. Pulm Pharmacol Ther 2008; 21: $115-124$.

5 Nguyen LP, Omoluabi O, Parra S, et al. Chronic exposure to beta-blockers attenuates inflammation and mucin content in a murine asthma model. Am J Respir Cell Mol Biol 2008; 38: 256-262.
6 Nguyen LP, Lin R, Parra S, et al. $\beta_{2}$-adrenoceptor signaling is required for the development of an asthma phenotype in a murine model. Proc Natl Acad Sci USA 2009; 106: 2435-2440.

7 Hanania NA, Singh S, El-Wali R, et al. The safety and effects of the $\beta$-blocker, nadolol, in mild asthma: an open-label pilot study. Pulm Pharmacol Ther 2008; 21: 134-141.

8 Lipworth BJ, Williamson PA. $\beta$ blockers for asthma: a doubleedged sword. Lancet 2009; 373: 104-105.

9 Lima DR, Turner P. Propranolol increases reduced $\beta$-receptor function in severely anxious patients. Lancet 1983; 2: 1505.

10 Lima DR, Turner P. $\beta$-blocking drugs increase responsiveness to prostacyclin in hypertensive patients. Lancet 1982; 2: 444.

DOI: 10.1183/09031936.00003210

\title{
Endobronchial metallic clips to guide high-dose external-beam radiotherapy in radio-occult lung cancer
}

\section{To the Editors:}

As a result of the increased sensitivity of videobronchoscopy (including narrow-band and video autofluorescence imaging) and a specific interest in surveillance of pre-invasive lesions, an increase in diagnosis of radiographically occult lung carcinoma (ROLC) can be anticipated. Described for the first time in the late 1970s by MARTINI and MELAMED [1] and in the early 1980s by CORTESE et al. [2], surgery still remains the treatment of choice for ROLC [3]. However, patients can be functionally inoperable due to comorbidity, advanced age, multiple primary lesions or irresectable, centrally localised tumours, or because they refuse surgery [2]. Therefore, varieties of endoscopic techniques, such as photodynamic therapy, cryotherapy, laser therapy, electrocautery and brachytherapy, were developed as alternatives to surgery [3-5]. The combination of high-dose external-beam radiotherapy (EBRT) with intraluminal radiotherapy (IR) using low [6-8], middle [9] and high dose-rate [10] iridium-192, has been investigated in ROLC with promising results. EBRT has obvious advantages to surgery, as it is less invasive and better tolerated by the patient. A major issue is, however, the localisation of the tumour for the guidance of EBRT, since these tumours are radiologically occult. Previously, in those studies combining EBRT with IR [6-10], localisation of tumour was determined under fluoroscopy using the tip of the bronchoscope. Radiation was given using small anteriorposterior opposed portals. Obviously, this is less reliable, precise and comfortable, as might be anticipated. To overcome this problem, we hypothesised that metallic clips, the same as used in gastroenterology to obtain haemostasis, could be used as beacons to locate the tumour during EBRT. In a postoperative setting, the same principle is often used to orient EBRT in incomplete resections. Radiation fields are collimated using metallic clips placed by the surgeon.

In a prospective pilot series (June-October 2008) we assessed the feasibility and safety of EZ-Clips HX 610-090 (Olympus, Aartselaar, Belgium) in inoperable patients with ROLC to guide high-dose EBRT. The standard length of these clips is $6 \mathrm{~mm}$ when deployed, and when opened the angle of the jaws is $90^{\circ}$ (fig. 1). Patient characteristics and tumour locations are summarised in table 1 . All four patients were male, smokers with a median age of 68 yrs and fitted the criteria for ROLC as described by the Japan Society of Lung Cancer [8]. They underwent white light and autofluorescence video bronchoscopy (fig. 1) because of haemoptysis (case 1), persistent infiltrate (case 2), screening for second primary (case 3) and persistant cough (case 4). Pathology of the endobronchial biopsies was invasive squamous cell carcinoma for all patients. One was staged cT2N0M0 and three were cT1N0M0. Staging was performed according to the 6th edition of the TNM (tumour, nodes, metastasis) Classification of Malignant Tumours [11]. Patients 1, 2 and 4 received brachytherapy with one fraction of $10 \mathrm{~Gy}$ at $1 \mathrm{~cm}$ from the catheter. Patient $3 \mathrm{did}$ not receive endobronchial brachytherapy because of a concurrent supraglottic tumour. Before EBRT, the patients underwent a second bronchoscopy to place two endobronchial metallic clips: one on the proximal carina and one on the distal carina, relative to the ROLC (fig. 1). This was performed under local anaesthesia and was well tolerated by all patients. The time needed to place the clips was estimated to be no longer than an ordinary flexible bronchoscopy with biopsies. Although one clip loosened immediately after placement, it could be removed using biopsy forceps. No other complications occurred. As can be seen in figure 1, the clips are radiographically identifiable. The clips were used for delineation of the clinical target volume on the treatment planning system (fig. 1). In addition, the clips served as beacons facilitating the correct positioning of the patient with conebeam computed tomography (CT) during hypofractionated radiation therapy $(8 \times 7.5$ Gy EBRT).

3-4 weeks after EBRT, the patients underwent another bronchoscopy to remove the endobronchial clips by means of biopsy forceps. In cases 1 and 4 , both clips were easily retrieved. In case 2, one of the clips was missing, and in case 3 both clips had disappeared. Thorough examination of all 

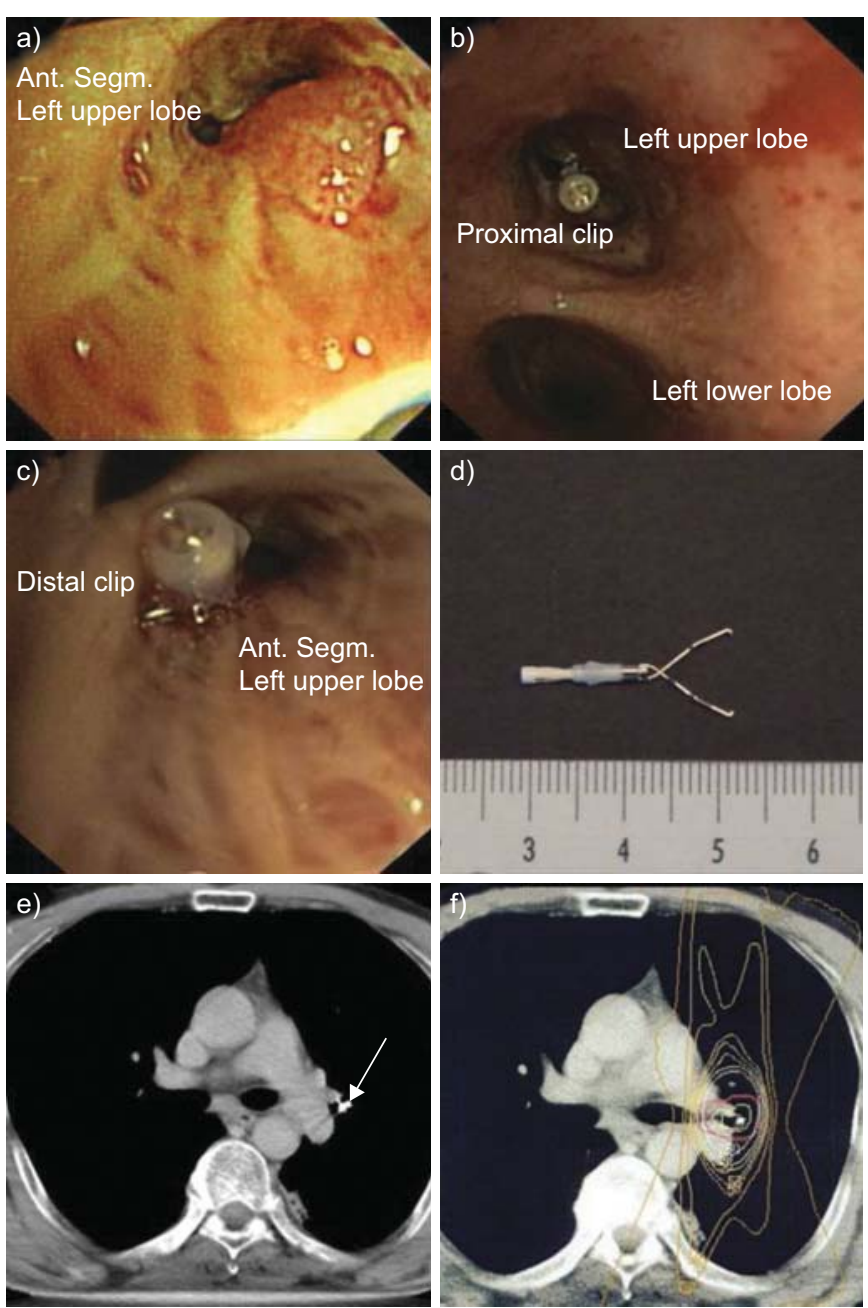

FIGURE 1. a) An endoluminal lesion in the anterior segment of the left upper lobe. b) Clip placed on the carina proximal of to the radiographically occult carcinoma (ROLC). Image taken from the left main bronchus. The carina seen is the secondary carina, with the upper part being the left upper lobe. c) Clip placed on the carina distal to the ROLC. Procedure performed after brachytherapy. The endoluminal lesion seen in a) has vanished. d) Close-up of an EZ clip. Scale is in $\mathrm{cm}$. e) Visualisation of the distal endobronchial clip as seen in c) on computed tomography images. Arrow shows endobronchial clip. f) Planning of external-beam radiotherapy with the field collimated using the EZ clips.

cone-beam computed tomography imaging revealed that one clip was already lost at the time of treatment planning, while two were lost during radiation therapy.

During the removal procedure, we also reassessed the mucosa and, interestingly, the macroscopic aspect of the tumour was unchanged in two cases, while in the other two, the tumour was no longer endoscopically identifiable (fig. 1). More importantly, endobronchial biopsies taken showed only inflammatory changes in all patients without signs of malignancy.

At follow-up, the patient treated with EBRT alone did very well, while the others treated with brachytherapy and EBRT developed either airway stenosis, infection or haemoptysis. The patient with haemoptysis succumbed 10 months after therapy. These complications fit with the data from FURUTA et al. [10]. Therefore, we think the adverse events experienced

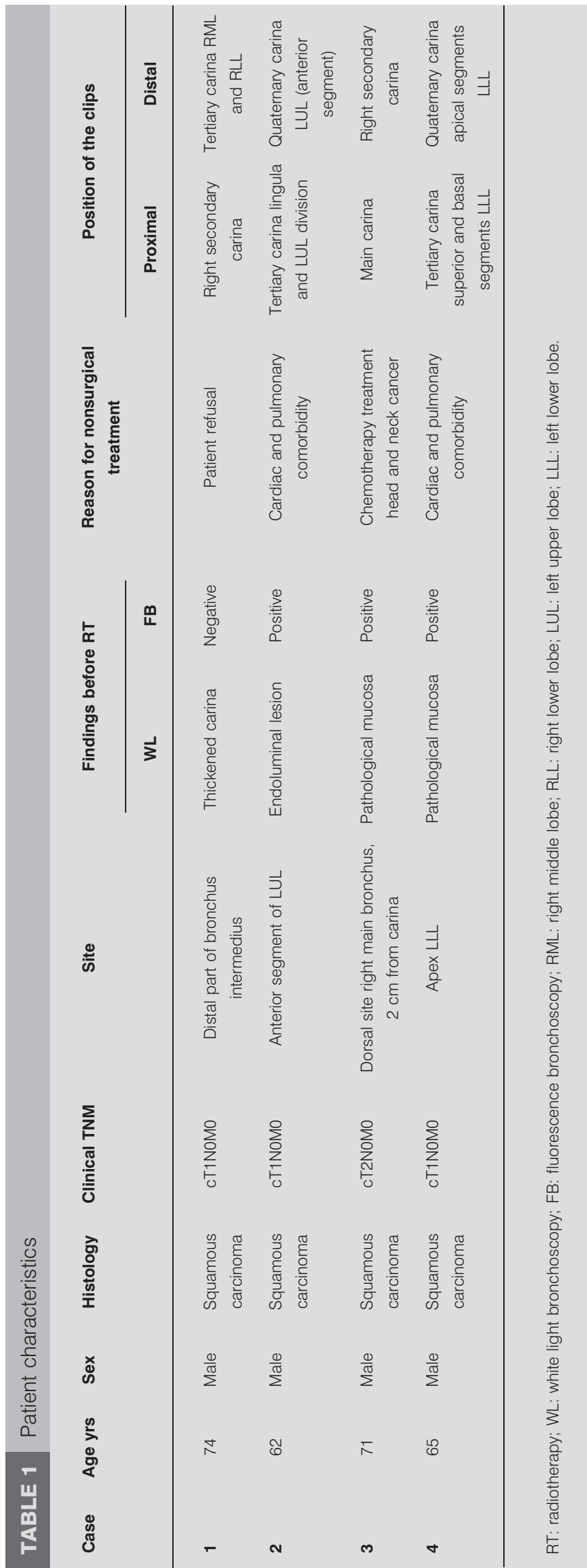


were due to the effects of brachytherapy and not to the use of metallic clips or EBRT.

In conclusion, although surgery remains the first choice to treat ROLC, a considerable number of patients are inoperable. EBRT is an alternative, but is hampered since the ROLC is effectively invisible. We report that the use of metallic clips placed during bronchoscopy can make ROLC visible for the radiation oncologist. The clips appear to be safe, well tolerated and removable in inoperable patients with ROLC who are candidates for EBRT. In the future, this technique could facilitate EBRT or even stereotactical beam radiotherapy in patients with ROLC. Prospective studies further investigating this technique are warranted.

T. Malfait*, M. van Eijkeren", J.P. van Meerbeeck ${ }^{\top}$ and K.G. Tournoy*

*Dept of Respiratory Medicine, "Dept of Radiation Oncology, Ghent University Hospital, and "Long Oncologisch Netwerk Gent (LONG), Ghent, Belgium.

Correspondence: T. Malfait, Dept of Respiratory Medicine, Ghent University Hospital, De Pintelaan 185, Ghent 9000, Belgium. E-mail: thomas.malfait@uzgent.be

Statement of Interest: None declared.

\section{REFERENCES}

1 Martini N, Melamed MR. Occult carcinomas of the lung. Ann Thorac Surg 1980; 30: 215-223.

2 Cortese DA, Pairolero PC, Bergstralh EJ, et al. Roentogenographically occult lung cancer. A ten-year experience. J Thorac Cardiovasc Surg 1983; 86: 373-380.
3 Kennedy T, McWillians A, Edell E, et al. Bronchial intraepithelial neoplasia/early central airways lung cancer. ACCP evidencebased clinical practice guidelines (2nd edition). Chest 2007; 132: 221S-233S.

4 Sutedja TG, van Boxem AJ, Postmus PE. The curative potential of intraluminal bronchoscopic treatment for early-stage non-smallcell lung cancer. Clin Lung Cancer 2001; 2: 264-270.

5 Vonk-Noordegraaf A, Postmus PE, Sutedja TG. Bronchoscopic treatment of patients with intraluminal microinvasive radiographically occult lung cancer not eligible for surgical resection: a follow-up study. Lung Cancer 2003; 39: 49-53.

6 Saito M, Yokoyama A, Kurita Y, et al. Treatment of roentogenographically occult endobronchial carcinoma with external beam radiotherapy and intraluminal low dose rate brachytherapy: second report. Int J Radiation Oncology Biol Physic 2000; 47: 673-680.

7 Fuwa N, Ito Y, Matsumoto A, et al. The treatment results of 40 patients with localized endobronchial cancer with external beam irradiation and intraluminal irradiation using low dose rate ${ }^{192}$ Ir thin wires with a new catheter. Radiotherap Oncol 2000; 56: 189-195.

8 Fuwa N, Kodaira T, Tachibana H, et al. Long-term observation of 64 patients with roentgenographically occult lung cancer treated with external irradiation and intraluminal irradiation using lowdose-rate iridium. Jpn J Clin Oncol 2008; 38: 581-588.

9 Fuwa N, Matsumoto A, Kamata M, et al. External irradiation and intraluminal irradiation using middle-dose-rate iridium in patients with roentgenographically occult lung cancer. Int $J$ Radiat Oncol Biol Phys 2001; 49: 965-971.

10 Furuta M, Tsukiyama I, Ohno T, et al. Radiation therapy for roentogenographically occult lung cancer by external beam irradiation and endobronchial high dose rate brachytherapy. Lung Cancer 1999; 25: 183-189.

11 Silvestri GA, Gould MK, Margolis ML, et al. Noninvasive staging of non-small cell lung: ACCP evidenced-based clinical practice guidlines ( $2^{\text {nd }}$ edition). Chest 2007; 132: 178S-201S.

DOI: $10.1183 / 09031936.00200209$

\section{lloprost-induced thrombocytopenia: a case proven by rechallenge}

\section{To the Editors:}

A 63-yr-old female underwent aortic and mitral valve replacement surgery (ATS 18 and $29 \mathrm{~mm}$, respectively; ATS Medical, Inc., Minneapolis, MN, USA) for aortic stenosis and mitral incompetence in August 2009. Pre-operatively, she was in New York Heart Association class III and exhibited comorbid hypertension, obstructive sleep apnoea (managed with nighttime continuous positive airway pressure), obesity (body mass index of $42 \mathrm{~kg} \cdot \mathrm{m}^{-2}$ ) and hypercholesterolaemia. Pre-operative right and left heart catheter investigation demonstrated a normal left ventricular ejection fraction, mean aortic valve gradient of $42 \mathrm{mmHg}$ (normal 0-10 $\mathrm{mmHg}$ ), valve opening area of $0.7 \mathrm{~cm}^{2}$ (normal $>2 \mathrm{~cm}^{2}$ ), mean pulmonary arterial pressure of $48 \mathrm{mmHg}$ (normal $12-16 \mathrm{mmHg}$ ), pulmonary vascular resistance of $225 \mathrm{dyn} \cdot \mathrm{s} \cdot \mathrm{cm}^{-5}$ (normal 100-200 dyn $\cdot \mathrm{s} \cdot \mathrm{cm}^{-5}$ ), pulmonary capillary wedge pressure of $34 \mathrm{mmHg}$ and cardiac output of $4.97 \mathrm{~L} \cdot \mathrm{min}^{-1}$. Her medication included an angiotensinconverting enzyme inhibitor, diuretics and aspirin.

Her post-operative course was complicated by a sternal wound infection, mediastinitis, pneumonia and renal failure requiring continuous high-flow haemodiafiltration. On the 14th postoperative day, she developed right heart failure (central venous pressure (CVP) of $25 \mathrm{mmHg}$, mean arterial pressure $\left(\bar{P}_{\mathrm{a}}\right)$ of $60 \mathrm{mmHg}$ and severely impaired right ventricular function on echocardiography) due to sepsis- and pneumoniarelated exacerbation of her initially mild post-capillary pulmonary hypertension. She required mechanical ventilation in a spontaneously breathing mode and circulatory support with noradrenalin and dobutamine. Treatment with inhaled iloprost (Ilomedin $\mathbb{R}$; Bayer Schering Pharma, Berlin, Germany) was commenced in order to reduce pulmonary arterial pressures and right ventricular work. A total of $10 \mu \mathrm{g}$ iloprost 